\title{
0 workshop ingredientes, alimentos processados funcionais e saúde no âmbito das atividades do Agropolo Campinas-Brasil
}

\author{
Ingredients, processed functional foods and health Workshop in the \\ context of the Agropolo Campinas-Brazil activities
}

\author{
Airton Vialta ${ }^{1 *}$, Luis Fernando Ceribelli Madi ${ }^{1}$ \\ 1 Instituto de Tecnologia de Alimentos - ITAL, Plataforma de Inovação Tecnológica, Campinas/SP - Brasil \\ *Corresponding Author: \\ Airton Vialta, Instituto de Tecnologia de Alimentos (ITAL), Plataforma de Inovação Tecnológica, Av. Brasil, 2880, Jardim Brasil, CEP: 13070-178, \\ Campinas/SP - Brasil, e-mail: avialta@ital.sp.gov.br
}

Cite as: Ingredients and processed functional foods Workshop in the context of the Agropolo Campinas-Brazil activities. Braz. J. Food Technol., v. 21 , e2017010, 2018

Received: Feb. 08, 2017; Accepted: Mar. 17, 2017

\section{Agropolo Campinas-Brasil}

O Agropolo Campinas-Brasil é uma plataforma interinstitucional fundamentada no conceito da inovação colaborativa que tem por objetivo desenvolver projetos de cooperação técnica em áreas estratégicas da bioeconomia tais como agricultura, alimentação, biodiversidade, bioenergia, química verde e desenvolvimento sustentável, visando à substituição gradual da economia atual, baseada em recursos fósseis. Participam do Agropolo Campinas-Brasil várias instituições da região de Campinas, entre elas o ITAL e a Associação Agropolis International, localizada em Montpellier na França, e que está servindo de modelo para o Agropolo Campinas-Brasil (AGROPOLO CAMPINAS-BRASIL, 2017a).

O principal resultado esperado é uma visão das pesquisas que devem ser desenvolvidas para impulsionar a inovação em bioeconomia. Para tanto, pretende-se aproximar os interesses da pesquisa acadêmica daqueles do setor produtivo, acessar novas fontes de financiamento para o desenvolvimento e a inovação tecnológica na área, formar grupos de pesquisa e incentivar parcerias, joint-ventures e investimentos, incentivar o desenvolvimento de novos produtos, promover processos inovativos, prospectar novos mercados para empresas localizadas na região de Campinas e incentivar a criação de startups e spin-offs (AGROPOLO CAMPINAS-BRASIL, 2017b).

Entre as atividades desenvolvidas pelo Agropolo Campinas-Brasil, está a execução do Projeto de Políticas Públicas em Bioeconomia (PPPBio), financiado pela FAPESP, cujo objetivo é mapear as áreas estratégicas em bioeconomia de Campinas e região, visando à criação de um ecossistema de classe mundial em bioeconomia, com três objetivos principais: criar produtos com maior valor agregado; aumentar o número de empregos formais; e reduzir as emissões de GEE.
O projeto PPPBio consiste na realização de 13 workshops, que abordarão diversas áreas da bioeconomia e fomentarão a interação entre diferentes entidades de pesquisa, ensino $e$ empresas. Os quatro primeiros workshops já foram realizados, sendo um deles o de ingredientes, alimentos processados funcionais e saúde.

\section{Workshop: ingredientes, alimentos processados funcionais e saúde}

Seguindo metodologia desenhada para a elaboração de roadmaps (LEAL, 2016), o workshop foi organizado em cinco seções, cada uma cobrindo um tópico-chave do tema principal. Foram elas: Cenário brasileiro: Ingredientes, alimentos funcionais e saúde; O consumidor brasileiro e a questão da comunicação; Adequação tecnológica de ingredientes; Adequação tecnológica de produtos; e Assuntos regulatórios. Cada seção teve um palestrante, que apresentou o estado da arte, e dois debatedores, que analisaram $e$ complementaram a apresentação, fomentando a elaboração de outras questões importantes. A parte final de cada seção foi aberta para perguntas, comentários e discussão com o público (AGROPOLO CAMPINAS-BRASIL, 2017c).

Na última etapa do workshop, todos os especialistas presentes discutiram as ações necessárias para desenvolver ainda mais a área de ingredientes e alimentos processados funcionais, tendo como pano de fundo os três objetivos principais: criar produtos com maior valor agregado; aumentar o número de empregos formais; e reduzir as emissões de GEE. Além das experiências de cada especialista, o workshop contou com as ideias apresentadas e discutidas nas outras cinco seções. Todas as contribuições foram coletadas e serão utilizadas para elaborar o roadmap da área. 
A metodologia empregada exigiu ainda a elaboração prévia pelo coordenador do evento de um termo de referência sobre ingredientes e alimentos processados funcionais e de position papers pelos palestrantes, abordando o conteúdo de suas apresentações e respondendo a perguntas apontadas por ocasião da definição do programa.

O conteúdo do programa, as perguntas e a escolha dos palestrantes e debatedores foram elaborados por um grupo de trabalho composto por especialistas do ITAL e da iniciativa privada.

\section{Principais resultados do Workshop}

Como apontado em estudos anteriores (ITAL, 2010; CGEE, 2014; ALVIM et al., 2014; VIALTA; REGO, 2014), o mercado de produtos funcionais tem crescido bem acima de alimentos e bebidas como um todo na última década, impulsionado por fatores como aumento e envelhecimento da população, maior consumo de alimentos processados, aumento do custo da saúde, crescimento das doenças crônicas não transmissíveis - DCNT, aumento de escolaridade e renda e maior interesse do consumidor pela inter-relação entre alimentos e saúde. É muito provável que esse mercado continuará a crescer nos próximos anos, restando a dúvida se tal crescimento conseguirá manter seu vigor, pois há fatores limitantes importantes, tais como um sistema regulamentar muito conservador, falta de mão de obra qualificada e falta de alinhamento com as tendências mundiais.

Além disso, o desenvolvimento de ingredientes funcionais e a comprovação científica de seus efeitos têm esbarrado na questão dos custos, pois eles têm que atender às normas de eficácia e segurança de uso, rotulagem e informação ao consumidor. Para tanto, exigem pesquisas mais complexas, maiores competências analíticas, equipamentos mais sofisticados e emprego de ensaios clínicos controlados duplos cegos e randomizados. Para reduzir tais custos, a indústria de ingredientes e alimentos tem ampliado as parcerias com a indústria farmacêutica, com ampla experiência na realização de ensaios clínicos (LAJOLO, 2014).

Outro ponto fundamental, mas difícil de quantificar, é a comunicação adequada com o consumidor. Pesquisas devem ser dedicadas a esse tema, pois o sucesso dos alimentos funcionais depende também da compreensão correta das alegações por parte do consumidor e de sua confiança.

$\mathrm{O}$ crescimento de ingredientes e alimentos funcionais dependerá do avanço das seguintes áreas tecnológicas (VIALTA et al., 2016):

- Novos tipos de processamento e/ou novos parâmetros de processo para os diferentes alimentos e bebidas, com o objetivo de proteger os compostos funcionais presentes nos produtos. Em muitos casos são necessárias tecnologias de barreira como microencapsulação e nanoencapsulação (ALVIM, 2014, 2015).

- Genômica nutricional, que compreende a nutrigenômica, efeito dos componentes da dieta na expressão gênica, e a nutrigenética, efeito da variabilidade genética ou polimorfismo nos componentes da dieta.

- Biologia de sistemas, que estuda as interações entre os milhares de genes humanos e os milhares de componentes da dieta e depende do avanço da genômica nutricional. Trata-se de uma área de alta complexidade, pois as interações se dão em diferentes fases (transcrição, tradução e metabolismo), em diferentes mecanismos (biodisponibilidade, transporte e reparo de DNA) e em diferentes órgãos e sistemas do organismo, incluindo o microbioma intestinal. O desenvolvimento da biologia de sistemas permitirá também estabelecer as bases da nutrição individualizada, da ação dos compostos bioativos e da demonstração da eficácia e das alegações de alimentos funcionais (LAJOLO, 2014).

- Microbioma humano, especialmente o microbioma intestinal, influencia o metabolismo energético, biodisponibilidade de nutrientes, sistemas endócrino e imunológico e até o sistema nervoso central, por meio do eixo intestino-cérebro. O microbioma intestinal varia com o indivíduo e com a dieta e, se sua interação harmônica com o organismo e equilíbrio forem rompidos, doenças podem se instalar (D'HONDT, 2016).

- Técnicas de identificação, extração e purificação de compostos bioativos, principalmente para estudos exploratórios da biodiversidade brasileira.

- Técnicas de fermentação, extração e purificação de compostos bioativos para possibilitar a clonagem em microrganismos de genes que codificam compostos bioativos isolados da natureza e assim viabilizar a produção comercial.

- Biologia sintética, buscando facilitar a clonagem de genes de interesse e o processo de fermentação (VIALTA, 2014).

- Síntese química, objetivando viabilizar a produção comercial de compostos bioativos isolados da natureza (CORREIA; OLIVEIRA, 2011).

O crescimento de ingredientes e alimentos funcionais no Brasil poderá ser prejudicado por lacunas tecnológicas, bem como barreiras, sendo as principais: falta de um plano nacional para o desenvolvimento do segmento; falta 
O workshop ingredientes, alimentos processados funcionais e saúde no âmbito das atividades do Agropolo Campinas-Brasil

Vialta, A.; Madi, L. F. C.

de mão de obra qualificada; baixo empreendedorismo; agências reguladoras não alinhadas com as tendências do mercado; elevados custos para a demonstração da eficácia; segurança dos ingredientes funcionais; falta de comunicação eficaz com os consumidores para elucidação dos reais benefícios dos alimentos funcionais (VIALTA et al., 2016).

\section{Conclusões do Workshop}

Estrategicamente, o mais importante para o Brasil é a construção e a implementação de um plano nacional para o desenvolvimento de alimentos funcionais e ingredientes, que inclua ações como: diagnóstico profundo do setor, qualificando e quantificando os recursos e a infraestrutura disponíveis e apontando barreiras e lacunas, bem como oportunidades; priorização de ações para eliminar barreiras e lacunas; priorização de áreas em que o Brasil tem vantagens comparativas e competitivas; e criação de políticas públicas necessárias para estimular o desenvolvimento do setor.

Alguns resultados esperados com a execução desse plano nacional seriam: criação de um centro multidisciplinar para apoiar e validar as provas científicas das propriedades funcionais, com alinhamento único e em consonância com as normas internacionais; criação de uma plataforma experimental de intervenção humana para enfrentar desafios como recrutamento e falta de padronização para ensaios clínicos, desenvolvimento de ferramentas clínicas não invasivas e confiáveis; equilíbrio entre ensaios clínicos controlados randomizados e estudos de população para determinar as melhores práticas de gerenciamento de assuntos relacionados à nutrição; identificação de biomarcadores validados de exposição e uso efetivo das ferramentas ômicas; integração de diferentes tipos de abordagens e métodos de estudo, tais como ciência básica, pesquisas clínicas e estudos de população; desenvolvimento de métodos e ferramentas para implementar o conhecimento da genômica nutricional, ciências ômicas e nanotecnologia; aumento do networking e do grau de internacionalização; realização de pesquisas interdisciplinares para determinar se as políticas de alimentação e nutrição estão atingindo os objetivos esperados; e adequação das agências reguladoras brasileiras que resultem em medidas tais como aprovar um código de práticas para a aplicação de alegações em alimentos e bebidas funcionais e reivindicações de bebidas; e aprovação de um código de práticas para o estabelecimento de novas categorias de alimentos e bebidas em sintonia com as tendências internacionais, que acelere a implantação da inovação no país.

Não resta dúvidas de que o desafio é grande, mas, se o Brasil quiser tirar proveito de seu enorme potencial para incrementar o desenvolvimento de ingredientes e alimentos processados funcionais, terá que se estruturar para isso. Um bom começo é estabelecer um plano nacional.

\section{Referências}

AGROPOLO CAMPINAS - BRASIL. Quem somos. Campinas, 2017a. Disponível em: <http://www.agropolocampinasbrasil. org/>. Acesso em: 08 fev. 2017.

AGROPOLO CAMPINAS - BRASIL. Resumo executivo. Campinas, 2017b. Disponível em: <http://www.agropolocampinasbrasil. org/>. Acesso em: 08 fev. 2017.

AGROPOLO CAMPINAS - BRASIL. Resumo executivo. Campinas, 2017c. Disponível em: <http://www.agropolocampinasbrasil.org/ workshop.html>. Acesso em: 08 fev. 2017.

ALVIM, I. D. Microencapsulação e nanotecnologia. In: INSTITUTO DE TECNOLOGIA DE ALIMENTOS - ITAL. Brasil Ingredients trends 2020. Campinas: ITAL, 2014. cap. 15, p. 337-357. Disponível em: <http://www.brasilingredientstrends.com.br/>. Acesso em: 16 nov. 2016.

ALVIM, I. D. Nananotecnologia: o futuro do setor alimentício? Revista Aditivos e Ingredientes, São Paulo, p. 7-9, 2015. Disponível em: <http://aditivosingredientes.com.br/edicoes/124/ nov-guia-funcionais>. Acesso em: 26 jan. 2017.

ALVIM, I. D.; FADINI, A. L.; CRUZ, C. L. C. V. Nutrição e funcionalidade. In: QUEIROZ, G. C.; REGO, R. A.; JARDIM, D. C. P. (Ed.). Brasil Bakery \& Confectionery Trends 2020. Campinas: ITAL, 2014. cap. 5, p. 119-159. 324 p. Disponível em: <www. bakeryconfectionerytrends.com. br>. Acesso em: 26 jan. 2017.

CENTRO DE GESTÃO E ESTUDOS ESTRATÉGICOS - CGEE. Sustentabilidade e sustentação da produção de alimentos no Brasil: interdependência alimentos, nutrição e saúde. Brasília: CGEE, 2014. v. 3, 172 p.

CORREIA, C. R. D.; OLIVEIRA, C. C. A evolução da química orgânica sintética: Quo vadis? Ciência e Cultura, São Paulo, v. 63, n. 1, p. 33-36, 2011.

D'HONDT, K. The microbiome, diet and health: assessing gaps in science and innovation. Brussels: Department Economy, Science and Innovation of the Flemish Government, 2016. 24 p. Disponível em <http://www.ewi-vlaanderen.be/sites/default/ files/microbiome_issues_paper_may_2016_kathleen_dhondt. pdf>. Acesso em: 26 jan. 2017

INSTITUTO DE TECNOLOGIA DE ALIMENTOS - ITAL. Brasil Food Trends 2020. São Paulo: ITAL/FIESP, 2010. 173 p. Disponível em: <www.brasilfoodtrends.com.br>. Acesso em: 26 jan. 2017.

LAJOLO, F. M. Desafios científicos e regulatórios. In: INSTITUTO DE TECNOLOGIA DE ALIMENTOS - ITAL. Brasil Ingredients trends 2020. Campinas: ITAL, 2014. cap. 17, p. 369-381. Disponível em: <http://www.brasilingredientstrends.com.br/>. Acesso em: 26 jan. 2017. 
O workshop ingredientes, alimentos processados funcionais e saúde no âmbito das atividades do Agropolo Campinas-Brasil

Vialta, A.; Madi, L. F. C.

LEAL, R. L. V. Development of technology roadmaps for creating a world-class bioeconomy ecosystem in Campinas. Campinas: Agropolo Campinas-Brasil, 2016. 19 p.

VIALTA, A. Biotecnologia. In: INSTITUTO DE TECNOLOGIA DE ALIMENTOS - ITAL. Brasil Ingredients trends 2020. Campinas: ITAL, 2014. cap. 16, p. 359-370. Disponível em: <http://www. brasilingredientstrends.com.br/>. Acesso em: 26 jan. 2017.

VIALTA, A.; MADI, L.; CARITÁ, E. (Coord.). Workshop term of reference (ToR). In: WORKSHOP BIOECONOMY "INGREDIENTES
FUNCTIONAL PROCESSED FOOD AND HEALTH", 4., 2016, Campinas. Workshop... Campinas: Agropolo, 2016. 22 p. Disponível em: <http://www.agropolocampinasbrasil.org/ arquivos/4_workshop_bioeconomia/ToR_WS4_Ingredients\&Food_ Agropolo_ITAL.pdf>. Acesso em: 31 jan. 2017.

VIALTA, A.; REGO, R. A. (Ed.). Brasil Ingredients Trends 2020. Campinas: ITAL, 2014. 389 p. Disponível em: <www. brasilingredientstrends.com.br>. Acesso em: 26 jan. 2017. 